1 Universidade Federal

do Rio Grande do Sul

(UFRGS), Programa de

Pós-Graduação em Saúde

Coletiva - Porto Alegre

(RS), Brasil.

tatidalmaso@gmail.com

2 Universidade Federal do Rio Grande do Sul (UFRGS), Programa de Pós-Graduação em Educação e Programa de Pós-Graduação em Saúde Coletiva - Porto Alegre (RS), Brasil.

dagmaremeyer@gmail.com

\section{Circulação e consumo de drogas em uma penitenciária feminina: percepções de uma equipe de saúde prisional}

\author{
Drug circulation and consumption in a female penitentiary: \\ perceptions of a prison health team \\ Tatiana Fraga Dalmaso', Dagmar Elisabeth Estermann Meyer²
}

RESUMO Este artigo tem como objetivo analisar a percepção de uma equipe de saúde prisional quanto à circulação e ao consumo de drogas feitos por mulheres privadas de liberdade em uma penitenciária. Para a produção do material empírico, realizou-se entrevista com os integrantes da equipe de saúde e observação do cotidiano de trabalho desta equipe. Com a análise realizada, verificou-se a existência de diferentes enunciações quanto à circulação e ao consumo de drogas na instituição. Pode-se dizer que as diferentes posturas adotadas pelos profissionais (de combate, tolerância e/ou incentivo ao uso dessas substâncias) decorre, entre outros fatores, do estatuto legal atribuído a elas: lícitas ou ilícitas.

PALAVRAS-CHAVE Equipe de assistência ao paciente. Mulheres. Prisões. Drogas ilícitas. Pesquisa qualitativa.

ABSTRACT This article aims to analyze the perception of a health team regarding the circulation and consumption of drugs by women deprived of their liberty in a penitentiary. For the production of the empirical material an interview was conducted with the members of the health team and the observation of the daily work of such team. With the analytical exercise carried out it was possible to verify the existence of different statements regarding the circulation and consumption of drugs in the institution. It can still be affirmed that the different positions of combat, tolerance or incentive to the use of these substances derives, among other factors, from the legal status attributed to them: licit/illicit.

KEYWORDS Patient care team. Women. Prisons. Street drugs. Qualitative research. 


\section{Introdução}

Esse artigo desdobra-se de uma dissertação realizada no Programa de Pós-Graduação em Saúde Coletiva da Universidade Federal do Rio Grande do Sul que teve como um de seus objetivos discutir como se define e implementa o cuidado em saúde para mulheres usuárias de drogas, presas em uma penitenciária feminina (DALMASO, 2017). Neste artigo, discutimos, em particular, a percepção da equipe de saúde prisional quanto à circulação e ao consumo de drogas feitos pelas mulheres privadas de liberdade.

De maneira geral, a efetivação do direito à saúde da população prisional, apesar de estar previsto na Lei de Execução Penal, na Constituição Federal e nos princípios do Sistema Único de Saúde, tem-se revelado um grande desafio. Essa população passa a ser reconhecida de forma específica nas políticas públicas de saúde a partir do ano de 2003, com a instituição do Plano Nacional de Saúde no Sistema Penitenciário (PNSSP) e, mais recentemente, com a aprovação da Política Nacional de Atenção Integral à Saúde das Pessoas Privadas de Liberdade no Sistema Prisional (PNAISP) (BRASIL, 2014A).

A penitenciária aqui estudada aderiu ao PNSSP e, posteriormente, à PNAISP, para viabilizar as instalações da equipe de saúde prisional e da Unidade Básica de Saúde (UBS) no interior da instituição. O 'Caderno sobre legislações de saúde no sistema prisional', elaborado pelo Ministério da Saúde (BRASIL, 2010), aponta que tanto o PNSSP quanto a PNAISP são estratégias para que as políticas de saúde cheguem à população prisional, o que inclui as políticas de saúde mental, nas quais se insere o cuidado a pessoas usuárias de drogas.

Segundo a Organização Mundial da Saúde, drogas são definidas como substâncias não produzidas pelo organismo que têm a propriedade de atuar sobre um ou mais de seus sistemas, produzindo alterações em seu funcionamento (CARLINI ET AL. 2001). Dessa forma, são consideradas drogas diversas
Substâncias Psicoativas (SPA): cocaína, crack, maconha, tabaco, medicações, determinados alimentos, bebidas entre outros.

Simões (2008), ao problematizar o consumo de drogas no campo dos estudos da cultura e da política, afirma que o consumo dessas substâncias é fenômeno recorrente e disseminado nas diferentes sociedades. Para o autor:

[...] os múltiplos modos pelos quais essa existência e esses usos são concebidos e vivenciados variam histórica e culturalmente. 'Drogas' não são somente compostos dotados de propriedades farmacológicas determinadas, que possam ser natural e definitivamente classificadas como boas ou más. Sua existência e seus usos envolvem questões complexas de liberdade e disciplina, sofrimento e prazer, devoção e aventura, transcendência e conhecimento, sociabilidade e crime, moralidade e violência, comércio e guerra. (SIMÕES, 2008, P. 13).

No campo discursivo que envolve o uso de drogas, há diferentes entendimentos sobre o consumo dessas substâncias e seus significados. Um exemplo dessa diferença pode ser visualizado no contexto da indústria farmacêutica e da de bebidas alcoólicas, no qual o comércio e o consumo têm crescido amplamente ao longo dos anos. Já a regulamentação sobre o consumo e o comércio de substâncias psicoativas consideradas ilícitas - como cocaína, crack e maconha - tem sido marcada pelo paradigma proibicionista conhecido como 'Guerra às Drogas' (ROMANI, 1999). Esta 'Guerra às Drogas' produz importante impacto na esfera social; e aqui, portanto, são problematizados os efeitos deste encontro/confronto na articulação entre os setores públicos da segurança e da saúde.

Atualmente, o Sistema Nacional de Políticas Públicas sobre Drogas (Sisnad), instituído pela Lei $\mathrm{n}^{\circ} 11.343 / 06$, é o documento que estabelece normas para a repressão à produção não autorizada e ao tráfico de drogas. Nessa lei, apesar de o porte de droga 
1 No universo do tráfico, a 'boca' é o local onde se vendem drogas ilícitas. ilícita continuar sendo considerado crime, o sujeito usuário/dependente não é mais penalizado com a privação de liberdade. Nesses casos, são aplicadas medidas socioeducativas como advertência sobre o uso de drogas, prestação de serviços comunitários ou medida educativa de comparecimento a programa educativo (BRASIL, 2006).

Carvalho (2013), ao estudar essa lei, afirma que ela não estabelece critérios precisos para diferenciar usuários de traficantes, desta forma, um amplo poder criminalizador fica à disposição das instituições de controle penal. Segundo o autor, isso se dá pela proliferação de

[...] metarregras que se fundam em determinadas imagens e representações sociais de quem são, onde vivem e onde circulam os traficantes e consumidores. (CARVALHO, 2013B, P. 49).

O impacto dessa lei sobre o processo de criminalização de alguns indivíduos e grupos pode ser evidenciado no contexto prisional. No que se refere às mulheres privadas de liberdade, estima-se que $63 \%$ estão encarceradas pela acusação do tráfico de drogas (BRASIL, 2014B). Segundo a Superintendência de Serviços Penitenciários do Rio Grande do Sul (SUSEPE, 2016), na instituição estudada, esse número é maior, girando em torno de $90 \%$ das mulheres. A política sobre drogas adotada no País impacta, especialmente, mulheres que vivenciam situações de vulnerabilidade social: de modo geral, as presas são jovens, negras, pobres e possuem baixa escolaridade (BRASIL, 2014B).

A Política Nacional de Atenção às Mulheres em Situação de Privação de Liberdade e Egressas do Sistema Prisional menciona, no texto, que muitas das mulheres presas são usuárias de drogas; que algumas realizam serviços no tráfico (como transporte e pequeno comércio) e que, em menor escala, realizam atividades voltadas à gerência da boca' (BRASIL, 2014B).

Na população em geral, o consumo de SPA por mulheres tem aumentado nos últimos anos e tem sido reconhecido como uma importante questão de saúde pública (LARANJeIRA, 2012). Entretanto, dados sobre o consumo de drogas entre a população prisional são ainda bastante escassos, e acredita-se que a falta de informações sobre sua circulação e consumo em estabelecimentos prisionais pode estar relacionada com a complexidade de discutir esses fenômenos em instituições de segurança pública.

Mello, ao entrevistar 287 mulheres privadas de liberdade em uma penitenciária feminina, constatou que $62,4 \%$ são acusadas de tráfico de drogas e que $44 \%$ apresentavam critérios diagnósticos para a dependência de SPA - principalmente o álcool, seguido de maconha, cocaína e crack (MELLO, 2008). Quitete et al. (2011) realizaram um estudo transversal com 134 mulheres que se encontravam em uma penitenciária na cidade do Rio de Janeiro. Segundo o estudo, 53\% das entrevistadas disseram que consomem substâncias ilícitas, diariamente, na instituição. Assim, há indicativos de que existem mulheres privadas de liberdade que são usuárias de drogas e que continuam a consumi-las no interior das instituições de segurança pública. Para além desses estudos, o uso de drogas nas instituições prisionais é mencionado em diferentes documentos e políticas, o que fornece algumas pistas sobre a importância de discuti-lo (BRASIL, 2014A, 2014B).

Diante do exposto até aqui, destaca-se a pergunta norteadora recortada para este artigo: qual a percepção da equipe de saúde prisional quanto à circulação e ao consumo de drogas feitos por mulheres privadas de liberdade em uma penitenciária feminina?

\section{Metodologia}

Trata-se, aqui, de uma pesquisa qualitativa inserida no campo da saúde coletiva. Segundo Bosi (2012), a pesquisa qualitativa produz respostas para algumas perguntas que a ciência positivista no campo da saúde não consegue responder. Para a autora, essa abordagem demanda 
[...] investimentos e estudos de processos humanos em lugar de tão somente estocar biotecnologias - que, a despeito de sua indiscutível importância, apenas serão úteis se e quando assimiladas culturalmente. (BOSI, 2012, P. 577).

Minayo (2010, P. 57) afirma que a pesquisa qualitativa

[...] se aplica ao estudo da história, das relações, das representações, das crenças, das percepções e das opiniões, produtos das interpretações que os humanos fazem a respeito de como vivem, constroem seus artefatos e a si mesmos, sentem e pensam.

Ela pode ser utilizada para conhecer, descrever e/ou dar visibilidade a processos sociais e grupos pouco conhecidos e possibilita construir novas abordagens, revisar e criar novos conceitos e categorias durante a investigação (MINAYO, 2010, P. 57).

Assim, com a abordagem qualitativa, pretende-se uma aproximação do cotidiano vivido por uma equipe de saúde em um território prisional, privilegiando o olhar para os elementos que não podem ser quantificados, visto que se referem às relações, às dinâmicas e às experiências estabelecidas entre os sujeitos da pesquisa. O trabalho de campo para a produção do material empírico foi realizado em uma instituição penitenciária feminina que faz parte do sistema prisional do estado do Rio Grande do Sul.

Inaugurada em 1944, até a construção de outra penitenciária feminina no ano de 2011, foi a única instituição prisional destinada a mulheres no estado. No momento em que a pesquisa foi realizada, havia, nessa penitenciária, 239 vagas disponíveis, e nela se encontravam 247 mulheres privadas de liberdade (SUSEPE, 2016). Quando é comparada a outras instituições prisionais, é possível dizer que, nela, as prisioneiras têm garantido, em certa medida, direitos como acesso à educação e aos serviços de saúde; de maneira geral, não há superlotação; as condições da estrutura física não são tão precárias; todas têm acesso à alimentação (são ofertadas quatro refeições por dia), e existe efetivo mínimo, ainda que não o ideal, das equipes de segurança, de saúde e do setor psicossocial.

A instituição conta com uma UBS e com equipe de saúde prisional constituída. Atualmente a equipe de saúde é composta por 12 profissionais, com cargas horárias de trabalho semanal distintas: 1 assistente social (40 horas), 1 dentista (40 horas), 2 técnicas de enfermagem (30 horas cada), 2 enfermeiras (30 horas cada), 1 nutricionista (40 horas), 1 psicóloga (40 horas), 1 médico pediatra (30 horas), 1 médico psiquiatra (4 horas) e 2 médicos clínicos (8 horas cada).

Para a produção do material empírico, utilizaram-se os procedimentos da entrevista e da observação. A entrevista (estratégia muito utilizada em pesquisas qualitativas) pode ser definida como 'conversas com finalidade' (MINAYO, 2010). A escolha pela entrevista semiestruturada se deu porque essa técnica amplia o escopo de fala relativamente ao que seria permitido por simples perguntas e respostas, na medida em que permite ao pesquisador "[...] encontrar os fios relevantes para o aprofundamento da conversa" (MINAYO, 2010, P. 265). Para a sua realização, foi organizado um roteiro temático que delimitava informações relevantes a serem cobertas pela entrevista, e esse roteiro permitiu ampliar e aprofundar a comunicação para compreender o ponto de vista dos entrevistados, provocando as narrativas de suas vivências e suas interpretações sobre a temática abordada. As entrevistas foram realizadas na própria instituição prisional, com os 12 trabalhadores da equipe de saúde.

A observação é um procedimento importante do trabalho de campo na pesquisa qualitativa, sendo entendida por algumas autoras como método em si mesmo para a compreensão da realidade (MINAYO, 2010). Nesta pesquisa, revelou-se um potente instrumento para produzir relações e familiaridade com a instituição estudada e com os seus sujeitos. Possibilitou, também, 
conhecer e vivenciar as rotinas e as dinâmicas do serviço de saúde. As observações realizadas na equipe de saúde foram anotadas em um diário de campo. Minayo (2010, P. 295) argumenta que o diário de campo "[...] é exatamente esse acervo de impressões e notas sobre as diferenciações entre falas, comportamentos e relações" que pode dar mais riqueza à pesquisa de campo.

Para a análise dos dados, realizou-se a transcrição de todas as entrevistas, que foram agrupadas com as anotações feitas no diário de campo. Para produzir um corpus de análise, selecionaram-se e organizaram-se trechos do material empírico relacionados com a questão norteadora deste estudo. Realizaram-se os movimentos analíticos na direção do que Minayo define como análise temática e que

[...] consiste em descobrir os núcleos de sentidos que compõem uma comunicação, cuja presença ou frequência signifiquem alguma coisa para o objeto analítico visado. (2010, P. 316).

Para esse tipo de análise, a presença de certos temas aponta estruturas de relevância e modelos de comportamento presentes ou subjacentes às falas e textos reunidos.

Por se tratar de um estudo no campo da saúde, foi aprovado pelo Comitê de Ética em Pesquisa da Universidade Federal do rio Grande do Sul (parecer $n^{\circ}$ 1.455.227) bem como atendeu às exigências da Resolução $n^{0}$ 466/2012 do Conselho Nacional de Saúde (BRASIL, 2012), que integra, em suas diretrizes, princípios e pressupostos da bioética como a autonomia, a não maleficência, a beneficência, a justiça e a equidade, para assegurar os direitos e os deveres dos participantes da pesquisa.

\section{Resultados e discussão}

Sobre a existência de drogas ilícitas na instituição, seu comércio e seu consumo, os membros da equipe de saúde enunciam diferentes pontos de vista. Alguns assumem que tais práticas acontecem na instituição, enquanto outros negam tanto o comércio quanto o consumo dessas substâncias. Esses pontos de vista podem estar associados a diferentes possibilidades de enunciação, das quais destacam-se duas que parecem ser mais significativas neste contexto: a (im) possibilidade de admitir a circulação e uso de SPA ilícitas em uma instituição de segurança pública como a penitenciária; e/ou a relação de confiança, pautada pelo sigilo profissional, que se estabelece com a prisioneira que conversa sobre o consumo - e seus efeitos - no interior da instituição.

Em duas entrevistas com integrantes da equipe de saúde, quando perguntados sobre a existência de drogas na penitenciária, foi referido:

[...] a gente até escuta que tem drogas aqui, como diria, pela rádio corredor... Mas como agora elas estão no sistema prisional, elas deixam de ser usuárias. (Participante 1).

A gente imagina que aqui não tenha drogas, mas tem várias épocas que existem revistas, suspeitas, tentam achar droga com alguém... (Participante 2).

Os dois excertos de fala sugerem que não há - ou não deveria haver - circulação e consumo de drogas no sistema prisional, que este deveria constituir um território 'livre' de SPA ilícitas. Ao assumir esse ponto de vista, os profissionais, mesmo quando sabem que tais substâncias circulam e são usadas nas galerias, colocam-se em uma posição na qual esse conhecimento não pode ser verbalizado. Entretanto, em outras entrevistas, alguns dos integrantes da equipe admitem o comércio e o consumo de drogas na penitenciária, mas entendem que isso se dá em menores quantidades e intensidade que na sociedade extramuros: 
Eu acho que tem consumo, mas diminui. Uma das questões é pelo acesso. Tu vai ter acesso só quando [a droga] entrar, e tem semanas que não vai entrar, então tu vai ficar sem. Então assim, tem, mas depende de outros fatores. (Participante 3).

Quando tinha uma firma e um monte de presas trabalhava, a droga era mais forte aqui... com a crise [financeira], fora o dinheiro começar a escassear, a família para de trazer dinheiro, aí tudo diminui, os celulares e as drogas. (Participante 4).

A gente sabe que tem dentro das galerias o comercio de drogas, aí tu vai dizer 'mas como entra?', mas de alguma forma entra... aqui dentro tem, menos do que na rua, mas tem. (Participante 5).

Assim, na perspectiva desses membros da equipe, a indisponibilidade de recursos econômicos e o controle exercido principalmente pela equipe de segurança parecem resultar em diminuição da quantidade de droga circulando na instituição; pois, com menos oferta e menos capital para adquiri-las, haveria menor possibilidade de consumo. É importante mencionar que, ao solicitar dados relacionados a quantas prisioneiras referem ser usuárias de drogas, quais as substâncias que consomem e com que frequência, foi dito que esse levantamento, de forma explícita e sistematizada, não era feito na instituição. Dessa forma, as informações que balizaram a análise feita resultam da percepção dos trabalhadores da equipe de saúde e das observações realizadas.

Durante o trabalho de campo, foi possível perceber, ainda, certa distinção entre posturas de combate, tolerância e/ou incentivo ao uso de drogas nessa instituição, e isto decorre, principalmente, do estatuto legal atribuído a essas substâncias: lícitas ou ilícitas. São posturas semelhantes ao que se encontra no contexto social mais amplo, nos serviços de saúde localizados fora dos muros das prisões, mas que também assumem certas características peculiares à instituição prisional.
No decorrer da pesquisa, foi possível verificar que o uso de tabaco pelas presas é prática frequente. Nas triagens realizadas pela equipe de saúde, quando questionadas sobre o uso de alguma droga, as prisioneiras usualmente respondiam: cigarro. Nas entrevistas realizadas com os integrantes da equipe de saúde responsáveis pela triagem, falou-se sobre o alto consumo de tabaco entre as prisioneiras - que giraria em torno de $50 \%$ da população. A alta incidência desse uso por mulheres prisioneiras também foi constatada na pesquisa sobre as condições de saúde de mulheres encarceradas realizada por Audi et al. (2016). Dessa forma, a prevalência de consumidoras de tabaco nas duas instituições prisionais estudadas é maior que na população em geral, que gira em torno de $15 \%$ (IBGE, 2013). Tal dado aponta tanto para as fronteiras ambíguas entre o que se define como droga quando se trata de uso lícito, com ou sem impacto sobre a saúde, quanto sinaliza a importância de ações que tenham como objetivo promover o cuidado em saúde para mulheres tabagistas.

Quanto ao consumo de bebidas alcoólicas, é possível descrever algumas peculiaridades. No decorrer do trabalho de campo, não se presenciou nenhuma situação relativa à demanda de cuidado em saúde relacionada com o consumo de álcool. Tal fato é interessante ante a constatação de que esta é a droga mais consumida no Brasil, reconhecida como a que mais danos tem causado à saúde da população e que seu uso por mulheres tem crescido de forma significativa (LARANJEIRA, 2012). Segundo pesquisa realizada pelo Instituto Brasileiro de Geografia e Estatística (IBGE), no Rio Grande do Sul, o percentual da população maior de 18 anos que consome semanalmente bebida alcoólica é de $31,2 \%$. Já o consumo semanal feito por mulheres está em torno de 17,3\% (IBGE, 2013). Apesar de ser considerada uma droga lícita, cujo uso é largamente aceito no País, no território prisional, o seu comércio e consumo são proibidos. 
Tal deslizamento, da condição de droga lícita para a de droga ilícita, permite fazer uma análise interessante, na direção de problematizar o que é lícito, e como se estabelece a legalidade de determinada substância. O exemplo permite argumentar, entre outras coisas, que a condição de legalidade e/ou ilegalidade não é determinada em função de um atributo inerente à substância, mas que esta classificação é datada e localizada, ou seja, ela se produz no âmbito do social e das culturas nas quais ela passa a funcionar como mecanismo de hierarquização, controle e regulação de sujeitos e de grupos.

$O$ uso de maconha na instituição foi relatado por alguns integrantes da equipe de saúde. Em uma das entrevistas, um trabalhador contou que, nos períodos em que a instituição esteve superlotada, não raro se sentia cheiro de maconha pelos corredores após o almoço. Assim, é possível relacionar a diminuição da população prisional ao aumento do controle sobre as prisioneiras - e seus visitantes - e deduzir que isso repercute na disponibilidade de drogas na instituição. Para alguns integrantes da equipe, o uso de maconha não seria, a priori, um problema que precisaria ser enfrentado, como se pode ver na fala abaixo:

\section{[...] Tem gente que diz que um pouquinho de ma- conha na cadeia não faz mal, a presa e o preso vão dormir e não estão incomodando... Mas isso também não é uma coisa escrita, na Susepe, é uma coisa velada... Se as presas usam diazepam, então um pouco de maconha também não tem problema. (Participante 4).}

O debate e as controvérsias sobre possíveis danos decorrentes do uso de maconha, a sua descriminalização e a legalização de seu comércio e consumo têm atravessado a sociedade contemporânea. Os argumentos se constroem no questionamento da toxicidade da substância e do baixo grau de dependência fisiológica que ela causaria, além da percepção de que a proibição de seu consumo e comércio é mais danosa à saúde coletiva que o uso em si (VIDAL, 2009). Tais alegações justificariam a necessidade de regulamentar o comércio e o consumo da substância. Nessa direção, diversos países, entre os quais Uruguai, Estados Unidos (em alguns estados), Holanda e Espanha, têm realizado experiências de regulamentação do comércio e do consumo de maconha. Essa discursividade produz efeitos e ressoa na fala de um membro da equipe de saúde. Para esse entrevistado, assim como se utilizam medicações para auxiliar as mulheres a suportarem a experiência do cárcere, pode-se também fazer uso de maconha, o que, em sua visão, contribuiria para manter a ordem na instituição.

Diferentemente do que acontece com a maconha, admitir e reconhecer a circulação e o consumo de crack e de cocaína evoca outros tipos de manifestação. Diz um membro da equipe de saúde:

A [prisioneira] que usa crack é discriminada, a maconha não tem problema, ninguém vai repreender ela, isso eu estou falando das próprias presas, eu já vi presas reclamarem que já saíram da cela porque tem craqueira. (Participante 4).

Ainda que sejam, a maconha e o crack, substâncias ilícitas, evidencia-se, nessas falas, que há diferenças entre elas quando se trata de admitir e/ou aceitar seu consumo no território penitenciário. Tal diferença também pode ser visualizada em equipes de saúde que se encontram fora do sistema prisional. Queiroz et al. (2014), em uma pesquisa feita com profissionais da rede de saúde mental e atenção primária, constataram que a concepção negativa sobre o usuário de drogas recai principalmente sobre pessoas que utilizam o crack, que apresentariam comportamentos desviantes e provocariam maior incômodo na ordem social. Já o álcool, o cigarro e a maconha gozaram de maior aceitabilidade entre os membros das equipes de saúde.

Cabe destacar, ainda, que nas diferentes conversas realizadas com os trabalhadores 
sobre o uso de drogas entre as prisioneiras, o termo 'droga' foi associado diretamente ao crack è cocaína. Por sua vez, o termo 'dependência química' foi utilizado para referir-se a efeitos do consumo dessas duas substâncias sobre elas. A terminologia 'craqueira', por sua vez, foi empregada em algumas entrevistas para se referir a mulheres que fazem uso abusivo de crack, quando é possível identificar a vinculação desta identidade de craqueira à determinada representação de mulher:

Tem umas [prisioneiras] que entram em estado deplorável, fétidas, magrinhas, que nem eu digo, sofreram maus tratos. Quando elas chegam já dá pra notar que elas são usuárias [de crack]. (Participante 5).

Essa representação que repercute na fala da equipe quando se refere a mulheres usuárias de crack tem a ver com o que se diz sobre quem são e como são as pessoas que o consomem, ditos que circulam em diferentes artefatos culturais. Nestes artefatos e nos conhecimentos que lhes dão sustentação, o crack tem sido apresentado como droga altamente viciante que acarreta um grave e grande problema social.

Gomes e Capponi (2011), ao discutirem o panorama atual que envolve o consumo de drogas, destacam que o crack tem estado em evidência. Segundo eles:

A constante aparição deste debate acontece na mídia, que tem alardeado a situação de forma distorcida, e também nas campanhas eleitorais, nos discursos de políticos e na definição de estratégias de ação e de políticas públicas. Ao mesmo tempo em que se reacende a discussão sobre o assunto, é surpreendente o quão superficial e cheia de preconceitos ela está acontecendo. (GOMES, CAPPONI, 2011, P. 9).

Outra reflexão que ainda precisa ser feita diz respeito ao uso excessivo de medicações controladas - psicofármacos - pelas presas. Apesar de não haver levantamento oficial, segundo relatos da equipe de saúde, aproximadamente $70 \%$ das prisioneiras fazem uso dessas medicações principalmente por sintomas relacionados com a depressão e com a ansiedade. $\mathrm{O}$ elevado número de mulheres privadas de liberdade que utilizam tranquilizantes também foi evidenciado e discutido na pesquisa realizada por Audi et al. (2016).

Em um estudo realizado na atenção primária em saúde, Rocha e Werlang (2013) analisaram o uso de psicofármacos pela população no mesmo município em que se encontra a penitenciária aqui estudada. A autora e o autor verificaram que a prevalência do uso pela população é de $7,3 \%$, destes, $72 \%$ são do sexo feminino. Vidal et al. (2013), em estudo desenvolvido com mulheres em um serviço da atenção básica, verificaram que $28,7 \%$ utilizavam psicofármacos. Em que pese a relevância destes números entre a população mais ampla, o uso de psicofármacos está prescrito para aproximadamente dois terços das mulheres dessa penitenciária; e, inclusive, por isso, o provimento dessas medicações assume um papel central na organização do trabalho diário da UBS e demanda significativo investimento de tempo para ser efetivado. Na maioria dos casos, são prescritas pelo médico psiquiatra, em atendimentos realizados às sextas-feiras, na UBS. São atendimentos clínicos, de curta duração, em que se busca "avaliar os sintomas, diagnosticar a patologia e prescrever a medicação para o tratamento" (Participante 6), como explica um integrante da equipe de saúde.

$\mathrm{Na}$ ótica de muitos membros da equipe de saúde, a maioria das prisioneiras passa a consumir essas medicações quando chega à penitenciária, parecendo ser esta uma estratégia para lidar com o sofrimento produzido dentro da própria instituição. Lima et al. (2013), ao realizar uma pesquisa sobre o contexto vivido por mulheres encarceradas, afirmam que:

A perda de laços afetivos familiares, de relacionamentos amorosos, a negação da maternidade, as fronteiras erguidas entre o ser e o 
ambiente, o medo, a tristeza, o desconforto, a ansiedade, a insegurança do futuro são experiências ameaçadoras à saúde mental destas pessoas. (LIMA, 2013, P. 455).

Durante a realização desta pesquisa, pôde-se observar que a distância da família e dos amigos, a ausência de atividades significativas, as condições da estrutura física, a incerteza quanto à sua condição jurídica são aspectos que contribuem para os processos de sofrimento das prisioneiras. Em grande medida, a medicação acaba sendo o recurso mais 'simples' (e aparentemente um dos únicos disponíveis) utilizado para lidar com esses fatores, como se vê nesta entrevista:

Elas usam muita medicação, tudo na base da medicação... Elas chegam aqui e se deparam com grades e não poder fazer nada, então elas querem a medicação ou pra dormir ou pra fugir de alguma situação... Eu acho que dormindo elas têm a ideia de que podem esquecer ou o tempo passa mais rápido. (Participante 5).

O uso dessas medicações parece, assim, relacionar-se com múltiplos fatores que envolvem a capacidade de lidar com o sofrimento produzido pela própria condição de privação de liberdade e com tudo o que decorre desta condição, sendo uma das possibilidades de as presas (sobre)viverem na instituição prisional. O consumo dessas substâncias extrapola avaliações diagnósticas da equipe de saúde, pois são solicitadas pelas próprias prisioneiras e também pela equipe de segurança quando, em sua perspectiva, a presa está passando por um processo de sofrimento ou quando ela apresenta comportamento 'difícil de controlar'.

Vargas (2008), ao esboçar uma genealogia das drogas, alerta para a necessidade de desnaturalização da distinção entre drogas e fármacos. $\mathrm{O}$ autor afirma que a maioria das sociedades contemporâneas mantém relações ambíguas com o consumo de drogas, nas quais, ao mesmo tempo que há políticas de repressão destinadas a algumas drogas, há intensa difusão e estímulo para o consumo de outras ('droga' em um sentido que também inclui os psicofármacos) (VARGAS, 2008). Assim, desde o ponto de vista de que tais substâncias integram o rol do que se pode nomear como droga, poder-se-ia considerar que as presas são, em sua maioria, usuárias de drogas neste caso, prescritas e disponibilizadas pela própria equipe de saúde.

\section{Considerações finais}

Com a realização deste estudo, foi possível verificar a existência de diferentes enunciações da equipe de saúde prisional quanto à circulação e ao consumo de drogas na penitenciária. Alguns membros da equipe afirmaram que não se evidencia circulação e consumo de drogas no interior da penitenciária. Essa percepção possibilita refletir a respeito de dois pontos que se desdobram dela: se não há circulação e consumo, a equipe não precisa ofertar cuidados em saúde para mulheres usuárias; ao afirmar que não existe circulação e consumo de drogas, esses integrantes deixam de considerar o uso de substâncias como cigarro e medicações, que também são classificadas como substâncias psicoativas. Pode-se então afirmar que as diferentes posturas de combate, tolerância e/ou incentivo ao uso dessas substâncias decorre, entre outros fatores, do estatuto legal atribuído a elas: lícitas ou ilícitas.

Nessa penitenciária, mais de $90 \%$ das mulheres estão presas por delitos relacionados com o comércio de drogas ilícitas; e, segundo parte da equipe de saúde, o comércio e consumo dessas substâncias continua a ser feito no interior da instituição. Ademais, o reconhecimento da circulação e do consumo de drogas na penitenciária torna-se importante, uma vez que é a partir desse reconhecimento que a equipe tem possibilidade de ofertar ações de cuidado em saúde para as prisioneiras que estejam realizando o 
consumo (para aquelas que desejam parar ou reduzir os danos decorrente do uso).

Outro ponto importante evidenciado na pesquisa refere-se ao volume de medicações psicotrópicas prescritas e massivamente consumidas pelas mulheres privadas de liberdade. Constatou-se que aproximadamente $70 \%$ das prisioneiras utilizam esse tipo de substância, índice muito superior quando comparado ao seu uso entre mulheres que estão fora do sistema prisional. Dessa forma, entende-se que esse é um fenômeno que demanda maiores estudos para ser problematizado em profundidade.

Por fim, espera-se que este estudo contribua para dar maior visibilidade à relação entre cuidado de saúde e uso de drogas em instituições prisionais na direção da efetivação do direito à saúde da população privada de liberdade, incluindo o cuidado em saúde. Deseja-se ainda que esta pesquisa estimule o desenvolvimento de outros estudos que tenham como finalidade produzir conhecimento a respeito dessas importantes temáticas.

\section{Colaboradores}

Ambas as autoras contribuíram para a concepção e elaboração do artigo, incluindo a elaboração do texto, revisão do conteúdo e análise dos dados.

\section{Referências}

AUDI, C. A. F. et al. Inquérito sobre condições de saúde de mulheres encarceradas. Saúde em Debate, Rio de Janeiro, v. 40, n. 109, p. 112-124, abr./jun. 2016.

BOSI, M. L. M. Pesquisa qualitativa em saúde coletiva: panorama e desafios. Ciência \& Saúde Coletiva, Rio de Janeiro, n. 17, v. 3, p. 575-586, 2012.

BRASIL. Lei $n^{\circ} 11.343$, de 23 de agosto de 2006. Institui o Sistema Nacional de Políticas Públicas sobre Drogas

- Sisnad; prescreve medidas para prevenção do uso indevido, atenção e reinserção social de usuários e dependentes de drogas; estabelece normas para repressão à produção não autorizada e ao tráfico ilícito de drogas; define crimes e dá outras providências. Diário Oficial [da] República Federativa do Brasil, Brasília, DF, 24 ago. 2006. Disponível em: <http://www.planalto.gov.br/ccivil_03/_ato2004-2006/2006/lei/111343.htm>. Acesso em: 18 out. 2017.

Ministério da Saúde. Conselho Nacional de Saúde. Resolução n. 466. Diário Oficial [da] República Federativa do Brasil, Brasília, DF, 12 dez. 2012. Disponível em: <http://bvsms.saude.gov.br/bvs/saudelegis/cns/2013/res0466_12_12_2012.html>. Acesso em: 18 out. 2017. 
. Ministério da Saúde. Secretaria de Atenção em Saúde. Departamento de Ações Programáticas Estratégicas. Legislação em saúde no sistema penitenciário. Brasília, DF: SAS, 2010.

. Ministério da Saúde. Ministério da Justiça.

Portaria Interministerial $\mathrm{MJ} / \mathrm{MS} \mathrm{n}^{\circ} 1$, de 2 de janeiro de 2014a. Institui a Política Nacional de Atenção Integral à Saúde das Pessoas Privadas de Liberdade no Sistema Prisional (PNAISP) no âmbito do Sistema Único de Saúde (SUS). Diário Oficial [da] República Federativa do Brasil, Brasília, DF, 17 jan. 2014.

Disponível em: <http://bvsms.saude.gov.br/bvs/saudelegis/gm/2014/pri0001_02_01_2014.html>. Acesso em: 18 out. 2017

Ministério da Justiça. Política Nacional de

Atenção às Mulheres em Situação de Privação de Liberdade e Egressas do Sistema Prisional. Brasília, DF: Ministério da Justiça, 2014b.

CARLINI, E. A. et al. Drogas Psicotrópicas: o que são e como agem. Instituto Maranhense de Estudos Socioeconômicos e Cartográficos (IMESC). Uningá, São Luís, v. 51, n. 3, p. 9-35, 2001.

CARVALHO, S. A política criminal de drogas no Brasil: estudo criminológico e dogmático da Lei 11.343/06. 6. ed. São Paulo: Saraiva, 2013.

DALMASO, T. F. Produção de territórios na interface da saúde com a segurança pública: cuidado em saúde para mulheres privadas de liberdade. 2017. 126 f. Dissertação (Mestrado em Saúde Coletiva) - Programa de PósGraduação em Saúde Coletiva, Universidade Federal do Rio Grande do Sul, Porto Alegre, 2016.

GOMES, B. R; CAPPONI, M. Álcool e outras drogas: novos olhares, outras percepções. In: Conselho Regional de Psicologia da $6^{\text {a }}$ Região (Org.). Álcool e outras drogas. São Paulo: CRPSP, 2012. p. 9-14.

\section{INSTITUTO BRASILEIRO DE GEOGRAFIA E} ESTATÍSTICA (IBGE). Pesquisa Nacional de Saúde. Rio de Janeiro: IBGE, 2013. Disponível em: <http://www. ibge.gov.br/home/estatistica/populacao/pns/2013/>. Acesso em: 15 set. 2017.
LARANJEIRA, R. et al. (Org.). Segundo Levantamento Nacional de Álcool e Drogas (LENAD). São Paulo: Inpad/ Unifesp, 2012.

LIMA, G. M. B. et al. Mulheres no cárcere: significados e práticas cotidianas de enfrentamento com ênfase na resiliência. Saúde em Debate, Rio de Janeiro, v. 37, n. 98, p. $446-456$, jul./set. 2013.

MELLO, D. C. Quem são as mulheres encarceradas? 2008.120 f. Dissertação (Mestrado em Psicologia Clínica) - Faculdade de Psicologia, Pontifícia Universidade Católica do Rio Grande do Sul, Porto Alegre, 2008.

MINAYO, M. C. S. O desafio do conhecimento: pesquisa qualitativa em saúde. 12. ed. São Paulo: Hucitec, 2010.

QUEIROZ, I. S. et al. Repertórios interpretativos de profissionais da rede de saúde mental e atenção primária de Belo Horizonte sobre uso de drogas. Saúde em Debate, Rio de Janeiro, v. 38, n. 100, p. 80-93, jan./mar. 2014.

QUITETE, B. et al. Transtorno de estresse pós-traumático e uso de drogas ilícitas em mulheres encarceradas no Rio de Janeiro. Revista de Psiquiatria Clínica. São Paulo, v. 29, n. 2, p.43-47, 2012.

ROCHA, B. S.; WERLANG, M. C. Psicofármacos na Estratégia Saúde da Família: perfil de utilização, acesso e estratégias para a promoção do uso racional. Ciência Et Saúde Coletiva, Rio de Janeiro, v. 18, n. 11, p. 32913330, 2013.

ROMANI, O. Las Drogas: sueños y razones. Barcelona: Ariel, 1999.

SIMÕES, J. A. Prefácio. In: LABATE, B. C. et al. (Org.). Drogas e Cultura: novas perspectivas. Salvador: EDUFBA, 2008. p. 13-23.

\section{SUPERINTENDÊNCIA DOS SERVIÇOES}

PENITENCIÁRIOS (SUSEPE). Dados estatísticos. 2016. Disponível em: <http://www.susepe.rs.gov.br/ conteudo.php?cod_menu=203\&cod_conteudo $=244>$. Acesso em: 15 de out. 2016 
VARGAS, E. V. Fármacos e outros objetos sócio-técnicos: notas para uma genealogia das drogas. In: LABATE, B. C. et al. (Org.). Drogas e Cultura: novas perspectivas. Salvador: EDUFBA, 2008. p. 41-64.

VIDAL, C. E. L. et al. Transtornos mentais comuns e uso de psicofármacos em mulheres. Caderno de Saúde Coletiva, Rio de Janeiro, v. 21, n. 4, p. 457-464, 2013.

VIDAL, S. A regulamentação do porte, cultivo e distribuição não comercial de cannabis sativa: um paradigma legal de redução de danos. In: NERY FILHO, A. et al. (Org.). Toxicomanias: incidências clínicas e socioantropológicas. Salvador: EDUFBA, 2009. p. 61-96.

Recebido para publicação em maio de 2017

Versão final em setembro de 2017

Conflito de interesses: inexistente

Suporte financeiro: não houve 